money and encouraged a foreign attendant to inject British performers with, believe it or not, an intramuscular nostrum of ox-blood and honey.

This sort of medievalism must be changed. We have many excellent team doctors but, clearly; we need urgently to raise the public image of sports medicine to the level where our sportsmen and women can take responsible care for granted.

The Journal is fortunate in acquiring not just the help but the active and enthusiastic personal support of our most distinguished team of section editors and members of the international editorial board. A glance at its membership will indicate just how far their commitment and authority in sports medicine can take BJSM. They are supported by a fine team of regional corresponding editors to help us avoid the inevitable constraints of life in one parish while working strongly within the global framework of that other founding institution of sports medicine-the International Federation of Sports Medicine (FIMS).

A major change sees the BASM Bulletin revived as a separately produced newsletter, sent only to members. This keeps the purely parochial within the parish and allows for its growth while BASM news of wider interest finds its place in the body of the Journal.

As we enter the next age, we must express our unbridled admiration for the stupendous efforts of Dr Henry Evans Robson as accoucheur to the infant Bulletin, then editor of the growing Journal for a quarter of a century. It is upon his broad shoulders that we can climb with confidence to achieve the full recognition and professionalization of sports medicine in Great Britain. It was with universal acclaim and admiration that the BASM chose to denote 'our Henry' as Editor Emeritus.

\title{
Chairman's Message
}

I would like to warmly welcome this new version of the British Journal of Sports Medicine and take the opportunity of welcoming members to a new era in the British Association of Sport and Medicine.

The advent of a new journal with professional publication should enable the activities of the British Association of Sport and Medicine to reach a very much wider audience and therefore, I hope, considerably expand the membership of BASM with kindred souls, many of whom may still be quite unaware of our activities.

The advent of the Society of Apothecaries Diploma Examination in Sports Medicine will, I hope, attract a great deal of interest among doctors in sports medicine as a legitimate activity and the launch of the new white paper by the government may make it possible to practice in sports medicine within the health service and be duly rewarded for so doing.

This is therefore a time of great change and it is up the Association, and in particular its officers, to grasp all the opportunities that arise for the expansion and recognition of sports medicine in this country. Through our new education officer we hope to be expanding the educational activities of the British Association of Sport and Medicine and although initially it may appear that the emphasis is very much towards the Society of Apothecaries Diploma Examination for doctors, we also hope to be laying on courses of interest to our other members, and indeed non-members as well.

The initial attempt to get data on all our members which would be of use to the Association and to people wanting local contacts interested in sports medicine and its various aspects has not been as successful as we hoped and we may be sending further questionnaires to members on the basis that it is important that we know what our members do and can inform the Sports Council and its regional officers of particular expertise in their area. I hope members will bear with me if they therefore receive in due course another questionnaire about themselves.

Dr Dan Tunstall Pedoe

Chairman

BASM

Br. J. Sports Med., Vol. 23, No. 1 